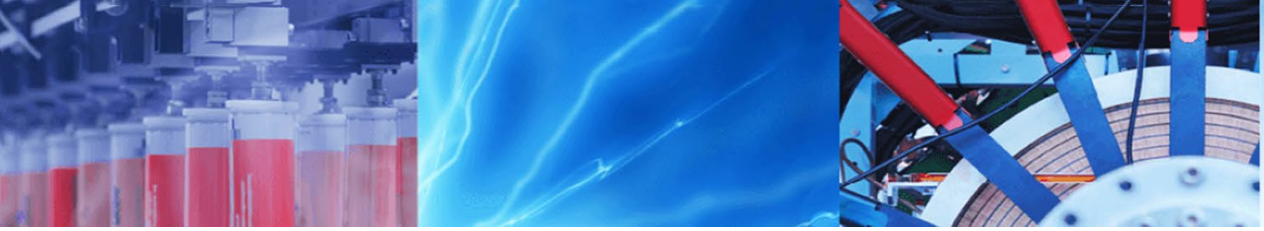

Research Article

\title{
Experimental and simulation study of the effect of cut-out defect in carbon fibres twill weave composite
}

\author{
Klaudio Bari ${ }^{1}[0] \cdot$ Sukru Sen ${ }^{1} \cdot$ Kiran Gulia $^{1}$
}

Received: 30 November 2019 / Accepted: 26 March 2020 / Published online: 3 May 2020

(c) Springer Nature Switzerland AG 2020

\begin{abstract}
The automated fibre placement (AFP) is an effective manufacturing process that produces a large complex structure with high quality at low secondary waste. Although, the AFP is highly accurate and reproducible and very common in the aerospace application, break and cut-out defect in the plies are inevitable. In this study, we have investigated 4 different types of geometrical cut-out defect that have an equal area $\left(38.4 \mathrm{~mm}^{2}\right)$ that cut from identical locations in the specimen plies. The effect of triangular, rectangular, square and circular cut-out defect has been investigated and compared to a virgin material that has no flaw or cut-out defect in the plies. It has been observed and hence reported that the circle induced flaw has caused $73 \%$ reduction in the impact strength due its $360^{\circ}$ distortion of carrying stress. The failure mode of the circular cut-out defect specimens was proven to be matrix crack due to miscarriage of the stresses in the fibre, while a pull-out fibres failure mode has been observed in the virgin specimen. The experimental work has been validated using FEA analysis that identically simulate the boundary condition of both bending and impact test.
\end{abstract}

Keywords Automated fibre placement · Geometrical cut-out defect · Failure mode · Matrix crack · Impact and flexural strength $\cdot$ Stress miscarriage

\section{Introduction}

The manufacturing induced imperfections in composites has been a major concern in engineering. The dynamic fracture behaviour of those imperfections or stress concentrators are of significant importance in terms of their service performance [1]. Many researchers have investigated the mechanic behaviour of fibre reinforced polymer matrix composites structures, such as tensile, compression and impact tests in the past decade [2], Even if experimental testing is widely used to investigate laminate's and component's strength for safety-critical components, it is inevitable to have a degree of uncertainty of the material performance [3]. Accompanying numerical simulations by means of advanced software within the framework of the finite element method (FEM) could help to reduce or partially eliminate this uncertainty [4].

Although the mechanical strength of composite materials is determined by the accuracy of a mechanical test, composite materials can be severely affected by number of defects during handling of the prepreg carbon fibre composite, manufacturing process and in-service life. For example, a pre-preg sheet cut, tool drop, twist and kink fibres during automated fibre placement (AFP) or impact damage during service life is likely to occur [5]. The occurrence of different damage modes depends on a variety of parameters such as the shape, size of the flaw in the prepreg sheet, pressure and temperature of the roller [6]. The damage appeared in the material and grows in the form of small delamination or cut-out defect during curing process and become invisible to detect in a non-destructive

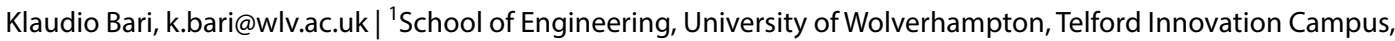
Wolverhampton TF2 9NT, UK. 

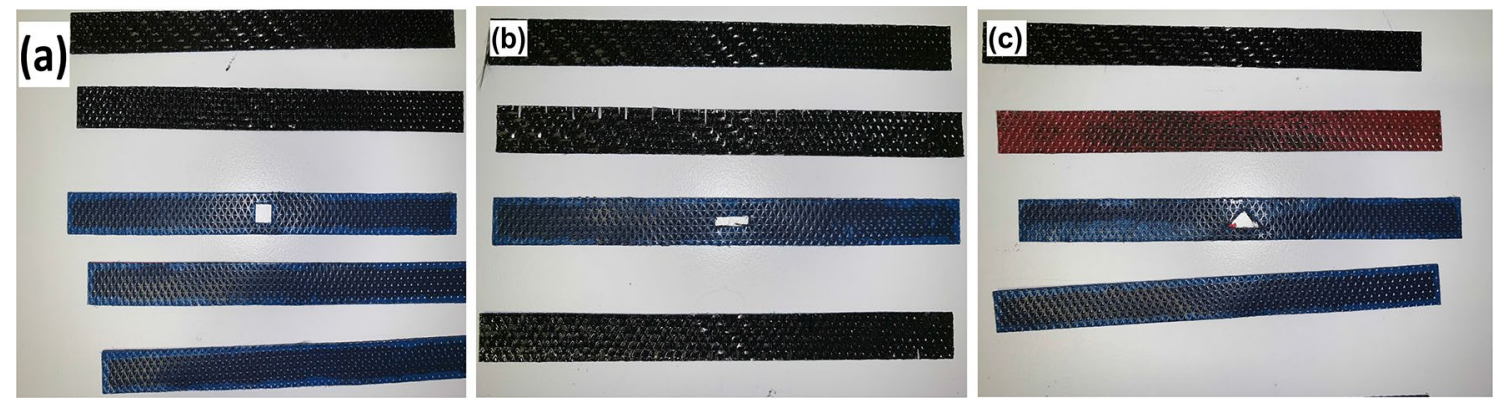

Fig. 1 Prepreg strips of the specimens have a square cut-out, $\mathbf{b}$ rectangular cut-out, $\mathbf{c}$ triangular cut-out defect

testing. In the case of impact damage, different types of damages can occur such as matrix cracking, delamination, fibre breakage. The damages are barely visible from outside but a reduction in stiffness and strength of materials can occur [1]. Also, specimens experience various types of fracture, matrix cracking, fibre breakage and delamination, where the impact shape shows a clear effect on the damage extent. Since damage always takes place inside composite layers, it is difficult to characterize it without using non-destructive testing. Many techniques have been used to detect the damage, which includes ultrasonic wave, radial, acoustic emission. Ultrasonic is easy to penetrate an object, and it is also good at the positioning the damage [7]. We have used both micro X-ray tomography and scanning electron microscope (SEM) to effectively evaluate the cut-out defect before and after the mechanical test.

Many researchers have investigated the effects of these damages in composites and presented an analytical method for the estimation of the compressive strength of the composites [8]. In their method, the analysis of the damaged composite was divided into three components: impact stress analysis prior to compressive of the sub laminate; eigenvalue analysis of the sub laminate and obtaining the compressive strength of the damaged composite. They have examined the effect of delamination geometry on the compressive failure of composite laminates [9], it was not clear what level and type of damage has been occurred in the laminates before impact test. Other researchers have applied finite element method (FEM) using a cohesive element to validated their results and growth in thin laminated composite with embedded flaws under compressive load [10]. It was concluded that the effects of flaws on bending in composite laminate is greatly depend on specimen length-width ratio, flaw shape, flaw size, and flaw depth in the specimen [11]. Also, researchers performed a crack growth analyses on composite panels containing embedded flaw using a geometrically non-linear FEM software, based on explicit dynamics model [12]. It was concluded that the effect of different geometrical cut-out defect has great influence on the deflection of composite laminate [13]. However, none of these studies have investigating specific geometrical cutout defect in the prepreg carbon fibres composite sheet when they appear before curing process. In this study, we have compared the mechanical strength of a reference specimen that has no embedded or induced geometrical cut-out defect with specimens that has various cut-out defect shapes in their 3rd ply. The experimental bending
Fig. 2 Schematic view of a top Circular embedded flaw for impact test $\mathbf{b}$ top circular embedded shaped flaw for bending test
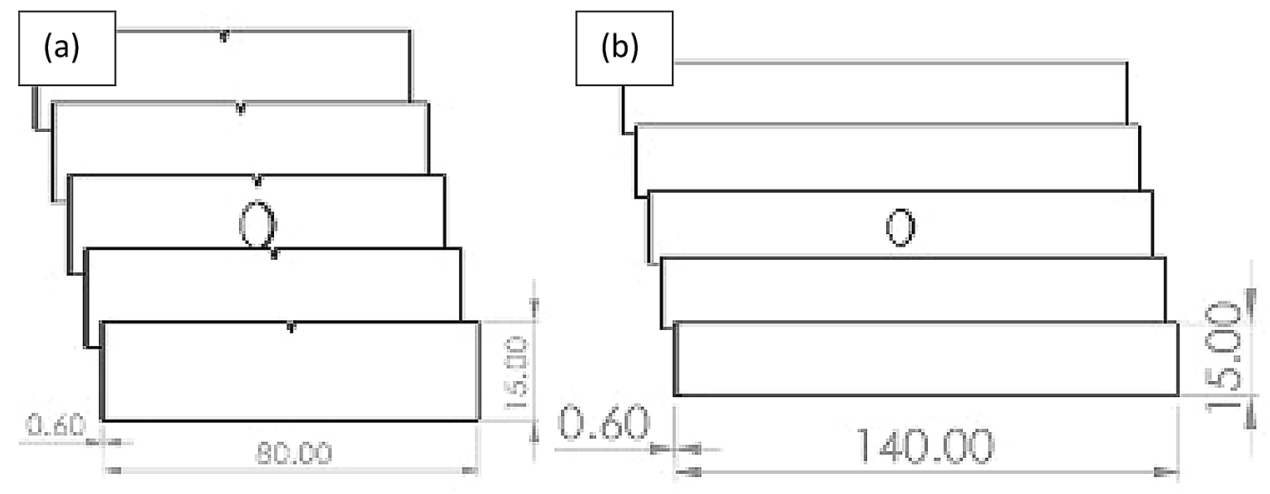
Table 1 List of the physical properties of the cut-out defect in the plies

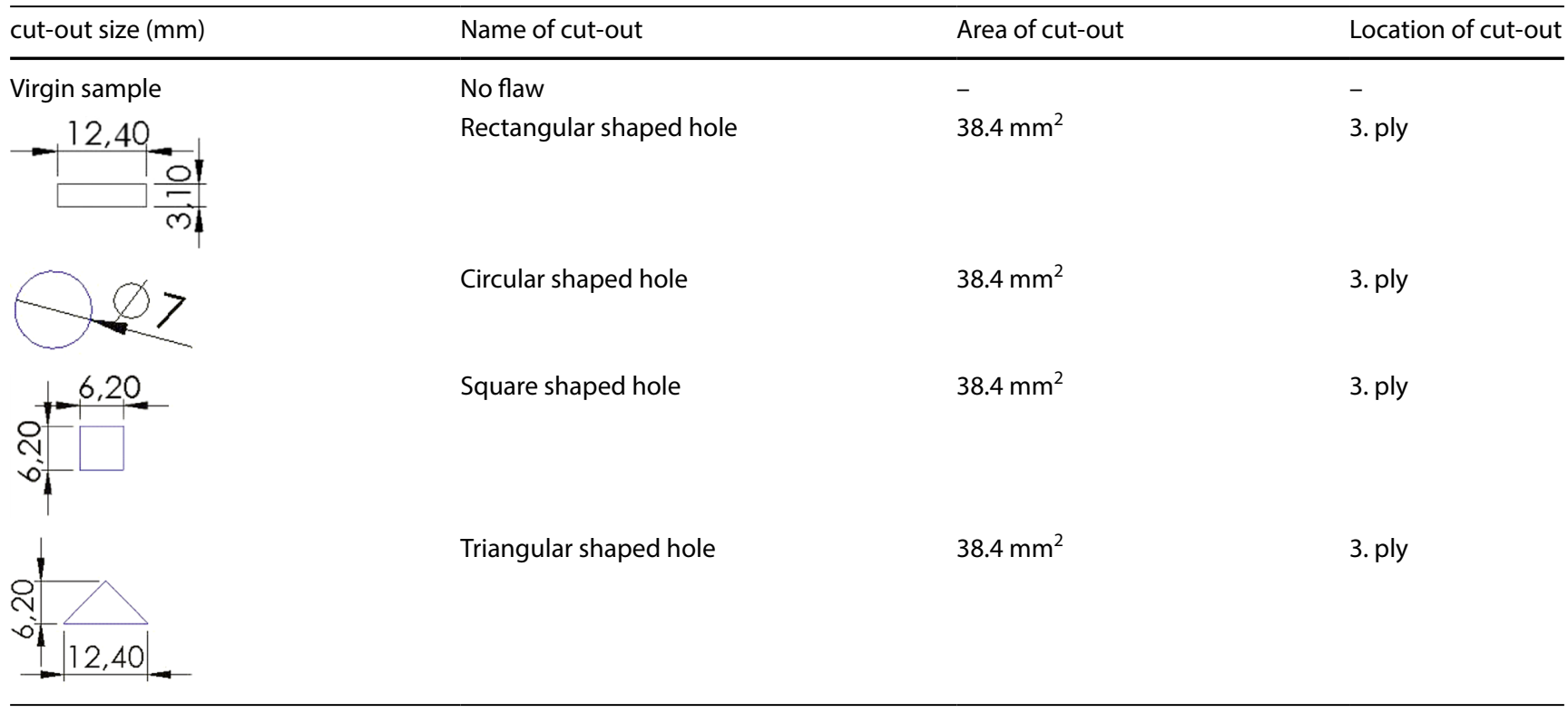

and impact test result have been validated using finite element analyses by applying identical boundary conditions that used in both bending and impact tests.

\section{Experimental}

\subsection{Materials and manufacturing}

The material used in this study is woven pre-preg Carbon Fibre reinforced composite known as $\mathrm{MTM}^{\circledR} 56$ manufactured by Solvay advanced composite. MTM56 series prepregs are based on $120^{\circ} \mathrm{C}\left(248^{\circ} \mathrm{F}\right)$ curing toughened, epoxy matrix resins that have fibre orientations Twill $2 \times 2$, $0^{\circ} / 90^{\circ}, 12 \mathrm{k}$ fabric. The sheet has a linear density of 120 gsm and $50 \%$ fibre/resin ratio. Two groups of samples were manufactured, group1 includes five samples of dimensions $140 \times 15 \times 3 \mathrm{~mm}$ prepared for bending test and group 2 includes five samples of dimension $80 \times 15 \times 3 \mathrm{~mm}$ prepared for impact test. Four samples from each group have geometrical cut-out of circle, rectangle, triangle, square shapes and one sample from each group is a reference sample (virgin) that does not have any flaws. The square, rectangular, triangular and circular shapes were cut-out from the 3 rd ply as shown in Fig. 1a-c respectively.

The shaped flaws were cut-out using Zund 35 digital sheet cutter that have an accuracy of $\pm 0.1 \mathrm{~mm}$. These plies were stacked together to form a beam, for illustration, the schematic of the circular cut-out defect specimens is shown in Fig. 2.
The cut-out defect dimension and its location in the plies before stacking them into beam in Table 1. All defects have been selected, so that they have equal areas to focus on their geometrical effect only.

All the specimens were prepared and cured using vacuum bagging system and cured in an oven as is shown in Fig. 3. Laminate plies or layered material were placed over an open mould surface and it was sealed in an airtight envelope bag. Specimens were cured in 3

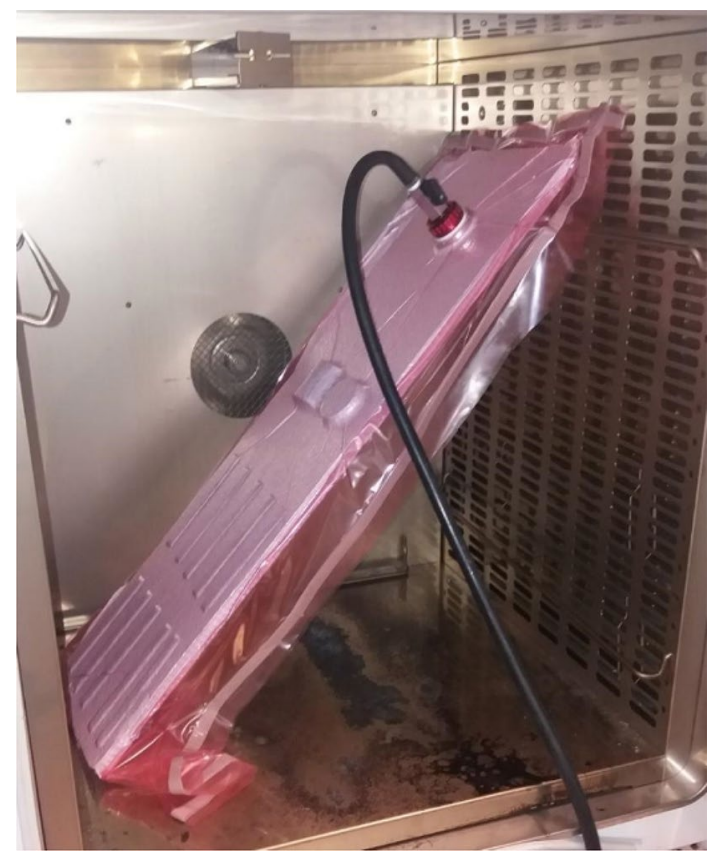

Fig. 3 Specimens curing in a vacuum bag and undergo curing cycle in an oven 
stages. The first stage is a heat ramping at $2{ }^{\circ} \mathrm{C} / \mathrm{min}$ to $70^{\circ} \mathrm{C}$ and hold for $180 \mathrm{~min}$. The second stage is a heat ramping at $2{ }^{\circ} \mathrm{C} / \mathrm{min}$ to $110^{\circ} \mathrm{C}$ and hold for $180 \mathrm{~min}$. The last stage is a cooling to room temperature at $1{ }^{\circ} \mathrm{C} / \mathrm{min}$.

The first heating stage is to decrease the viscosity of epoxy resin; thus, resin can penetrate and disperse into fibres before curing. After removing the specimen from the mould, the dimension of the samples was adjusted to the standard sizes using dry abrasive rotating disc to make them ideal for volume calculation $\left(\mathrm{cm}^{3}\right)$. The density of the specimens was calculated by dividing weight over volume values and listed in Tables 2 and 3 .

\subsection{Instrumental charpy impact test}

The specimens were tested using Instron CEAST 9050 Charpy test equipment as shown in Fig. 4a. The instrumented hammer is able to test nominal impact energies up $7.5 \mathrm{~J}$, impact velocities of $3.8 \mathrm{~m} / \mathrm{s}$ and fall angle of $150^{\circ}$. The specimens were notched to specified V-shape of $2 \mathrm{~mm}$ depth, opening angle of $45^{\circ}$ and a tip radius is $0.25 \mathrm{~mm}$ (Fig. 4b) according to BN EN ISO 179-2 standard for instrumented impact test of polymer composites.
Table 2 List of the physical properties of the samples for Impact test

Table 3 The physical properties of the samples for Bending test

Fig. 4 Instron CEAST 9050 Charpy test equipment and the test specimen and V- notch

\begin{tabular}{llllll}
\hline & Length $(\mathrm{mm})$ & $\begin{array}{l}\text { Thickness } \\
(\mathrm{mm})\end{array}$ & Width1 $(\mathrm{mm})$ & Mass $(\mathrm{g})$ & $\begin{array}{l}\text { Density1 } \\
\left(\mathrm{g} / \mathrm{cm}^{3}\right)\end{array}$ \\
\hline Virgin sample & 80 & 3 & 15 & 4.6 & 0.96 \\
Square shaped flaw & 80 & 3 & 15 & 4.5 & 0.92 \\
Triangle shaped flaw & 80 & 3 & 15 & 4.5 & 0.93 \\
Circle shaped flaw & 80 & 3 & 15 & 4.4 & 0.94 \\
Rectangle shaped flaw & 80 & 3 & 15 & 4.4 & 0.93 \\
\hline
\end{tabular}

\begin{tabular}{llllll}
\hline & Length $(\mathrm{mm})$ & $\begin{array}{l}\text { Thickness } \\
(\mathrm{mm})\end{array}$ & Width $(\mathrm{mm})$ & Mass $(\mathrm{g})$ & Density $\left(\mathrm{g} / \mathrm{cm}^{3}\right)$ \\
\hline Virgin sample & 140 & 3 & 15 & 7.6 & 1.04 \\
Square shaped flaw & 140 & 3 & 15 & 7.5 & 1.01 \\
Triangle shaped flaw & 140 & 3 & 15 & 7.5 & 1.02 \\
Circle shaped flaw & 140 & 3 & 15 & 7.3 & 1.00 \\
Rectangle shaped flaw & 140 & 3 & 15 & 7.4 & 1.02 \\
\hline
\end{tabular}
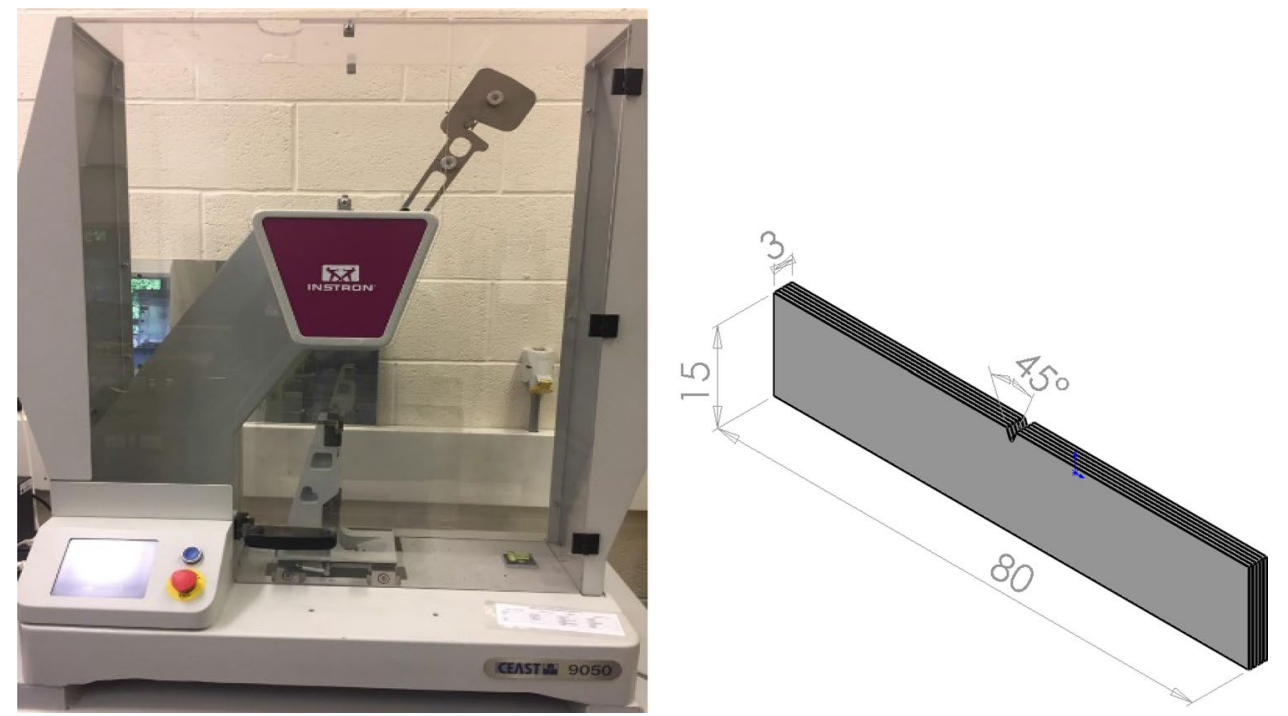

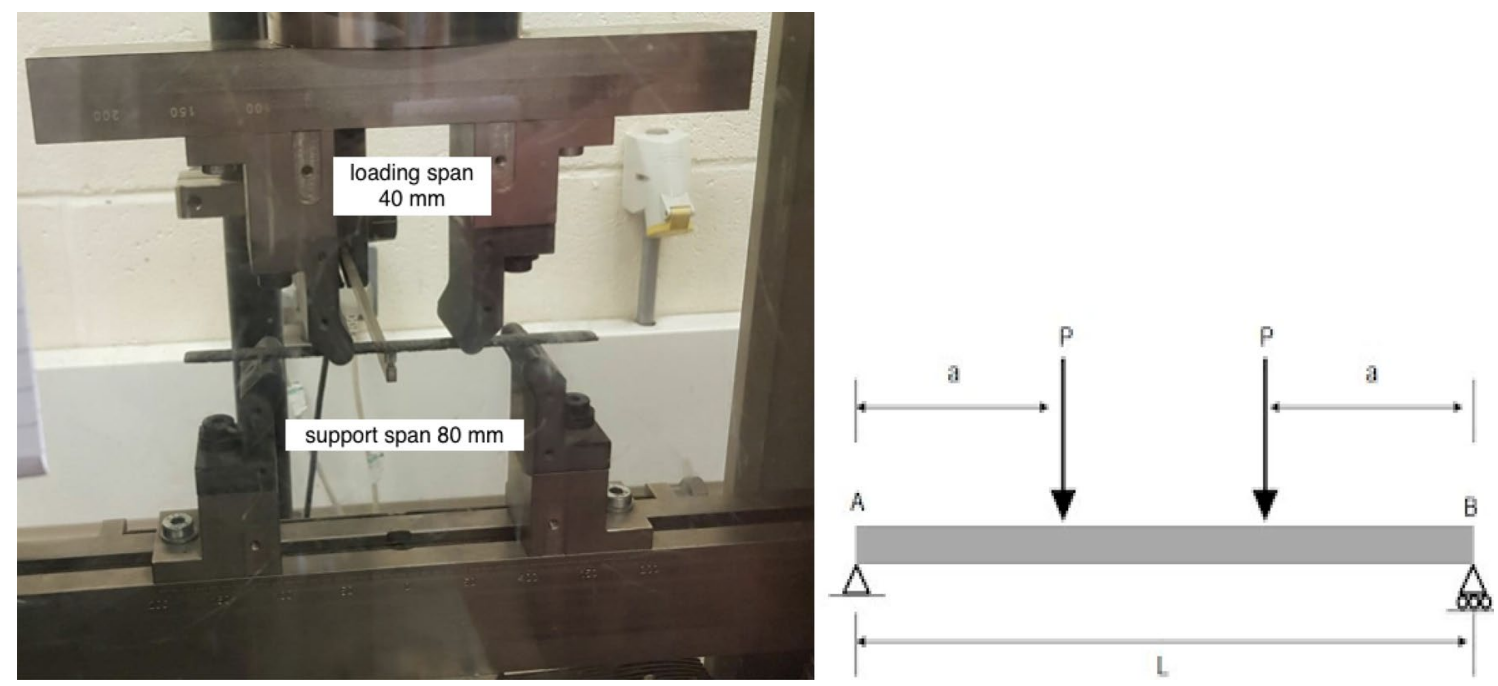

Fig. 5 Four-point bending test shows the loading span $40 \mathrm{~mm}$, support span $80 \mathrm{~mm}$

\subsection{Flexural test}

In order to determine flexural strength, a four-point bending test is in accordance with BS EN ISO 14,125: 1998 using a Zwick-Roell 1474 standard were used as shown in Fig. 5 .

The loading span was $80 \mathrm{~mm}$ while the loading span was $40 \mathrm{~mm}$. Tests were carried out at a pre-load speed of $5 \mathrm{~mm} / \mathrm{min}$ and then a test speed of $10 \mathrm{~mm} / \mathrm{min}$. A specimen linear extensometer was fitted to record accurate displacements. During the test, the displacement was restricted to maximum deflection of $20 \mathrm{~mm}$ to avoid damage to the extensometer. The flexural strength $\left(_{\sigma F}\right)$ and Young's modulus $\left(E_{F}\right)$ were determined by maximum loading till fracture. The maximum flexural stress otest specimen $\left(\sigma_{f}\right)$ has been calculated according to Eq. 1 and the Young's modulus ( $E$ ) were calculated according to Eq. 2.

$\sigma_{f}=\frac{3 F L}{4 b h^{2}}$ where $\sigma_{f}$ : Flexural stress, F: Applied load, L: support span $0.08 \mathrm{~m}$, b: Width of the specimen $(0.015 \mathrm{~m}) \mathrm{h}$ : thickness of the specimen $(0.003 \mathrm{~m})$

$E=\frac{F a\left(3 L^{2}-4 a^{2}\right)}{24 I \delta}$

$E$ : Flexural Modulus, $(\delta)$ : Deflection, I: second moment of area, a: L/4 (0.02 m).

\section{Finite element analysis}

The commercial finite element program, ABAQUS CAE 2018, was used to predict the strength of all specimens under bending and Impact test. The simulation work was carried out by using the explicit dynamics model. The model uses quantum shell composite model consist of 5 plies, each ply of thickness $0.6 \mathrm{~mm}$. A 2D sketch surface area of $38.4 \mathrm{~mm}^{2}$ in the shape of square, rectangular triangular and circular have been inserted in the third ply from dropdown tool as shown in Fig. 6a. This blank surface
Fig. 6 a Beam lay-out consist of 5 plies (each $0.6 \mathrm{~mm}$ ) has a square cut-out defect, b Th deflection of $6 \mathrm{~mm}$ has been set in the loading section in Abaqus CAE
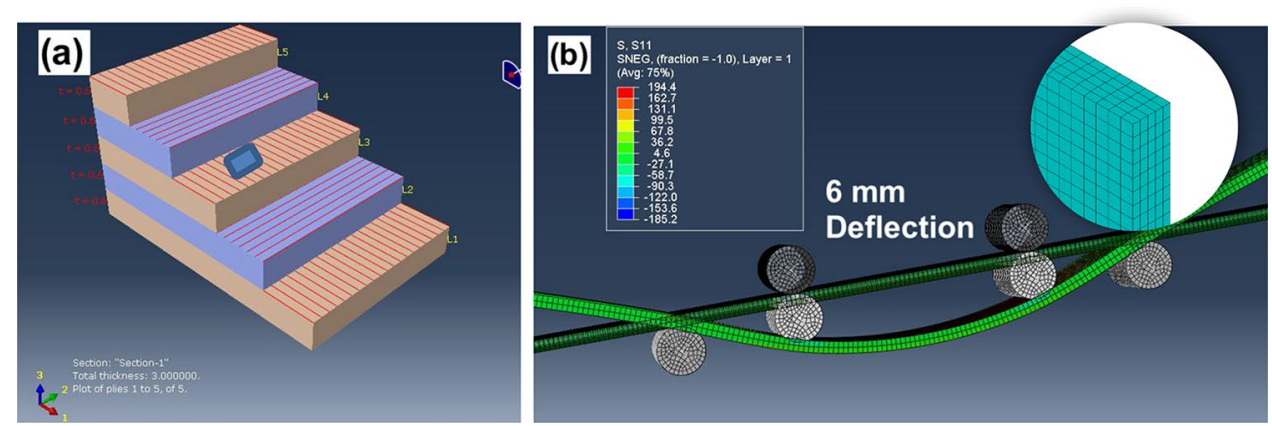

SN Applied Sciences A SPRINGER NATURE journal 
Fig. 7 a Bending test configuration, $\mathbf{b}$ Impact test configuration

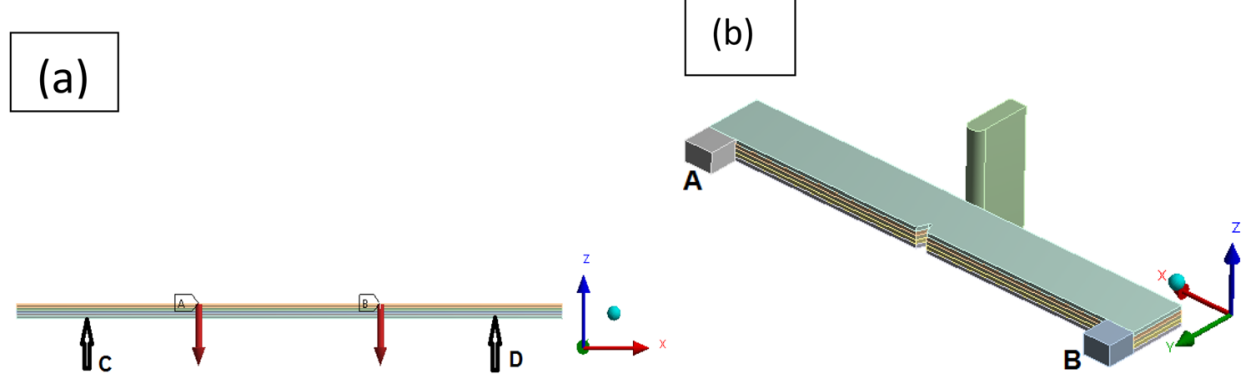

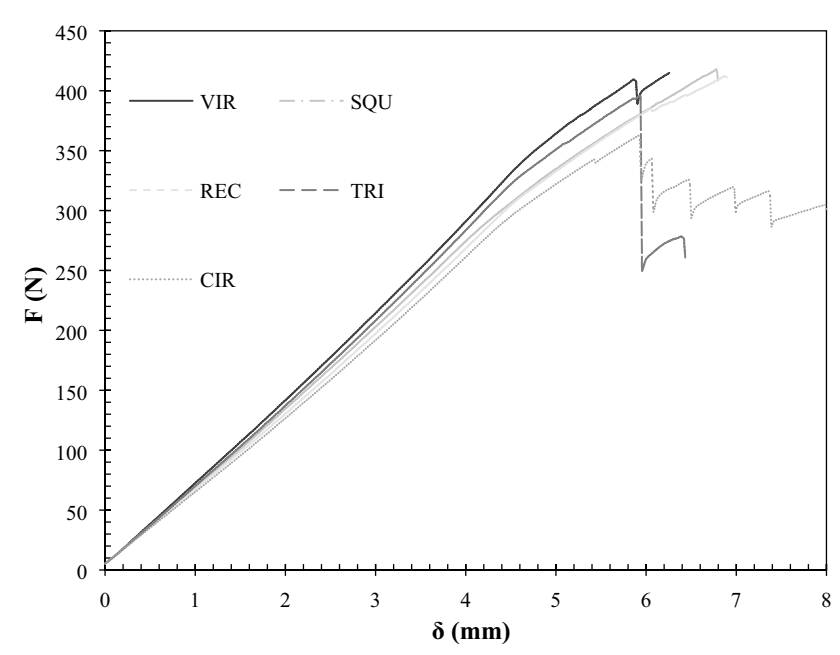

Fig. 8 Plot shows the correlation of the applied Force with deflection obtained from Zwick Roel 1474 testing rig

of the required shape is considered as cut-out defect and represents as a discontinuity of the fibre. The mechanical properties of the CFRP were used according to the manufacture data sheet for carbon fibre composite Twill, $2 \times 2 r$, $0^{\circ} / 90^{\circ}$ configuration. The Young's modulus E1, E2 set to be $70 \mathrm{GPa}$, in-plane Shear modulus G12 is $5 \mathrm{GPa}$, possion's ratio $v 12$ is 0.1 . For the impact simulation, part design and sketch icons were selected to create a new part and to sketch a two-dimensional model that is similar to criteria used in bending test. The 2-D drawing was extruded into a 3-D model with a thickness of $3 \mathrm{~mm}$ and have an identical $V$-notch and cut-out defects. The extruded model used in Abaqus simulation environment to create the model. A block pendulum was created by using the Volume Block option in the Modelling menu and impact velocity was set $3.8 \mathrm{~m} / \mathrm{s}$ in $0.001 \mathrm{~ms}$.

\subsection{Meshing}

3D was designed in the Solid module for performing the bending and impact analysis. This was defined in Abaqus CAE explicit dynamic model. For the Impact test analysis,
Table 4 List of the failing stresses and flexural modulus of all specimens

\begin{tabular}{llll}
\hline specimen & Force $(\max ) \mathrm{N}$ & $\begin{array}{l}\text { Failing stress } \\
\left(\sigma_{\text {fmax }} \mathrm{MPa}\right.\end{array}$ & $\begin{array}{l}\text { Flexural } \\
\text { modulus } \\
\mathrm{GPa}\end{array}$ \\
\hline Virgin (VIR) & 418.38 & 185.78 & 30.274 \\
Square (SQU) & 414.91 & 184.4 & 30.051 \\
Rectangle (REC) & 413.02 & 183.56 & 29.914 \\
Triangle (TRI) & 395.72 & 175.87 & 28.661 \\
Circle (CIR) & 363.12 & 161.38 & 26.300
\end{tabular}

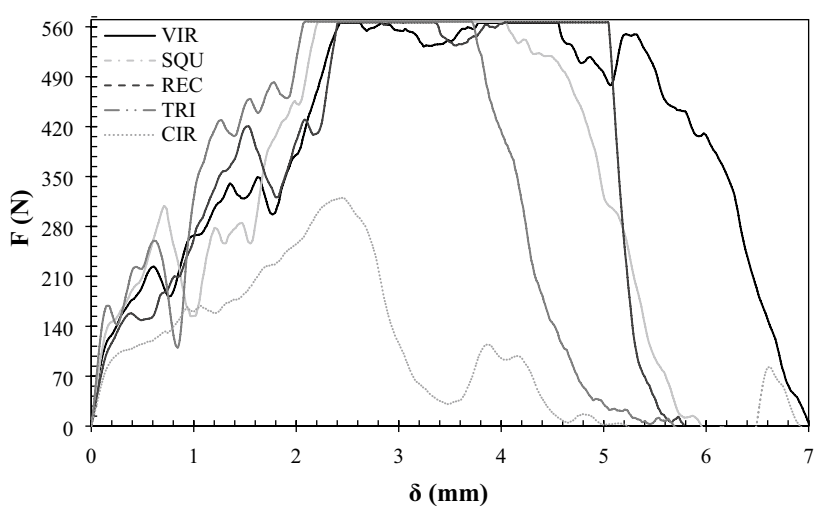

Fig. 9 Force displacement profile from experimental impact test

the test sample has 78,000 elements and for Bending test analysis, the sample has 60,100 elements. Figure $6 \mathrm{~b}$ shows the generated 3D solid mesh for both the beam and the roller in the bending simulation, a global seed size of $1 \mathrm{~mm}$ of polyhedral standard mesh has been selected in order to run each case effectively within $5 \mathrm{~min}$ solving time. While $0.1 \mathrm{~mm}$ seed size of tetrahedral mesh for curvature part in the part. Abacus will automatically identify any hole or defect as a curvature and use tetrahedral mesh around them. This option is available in mesh parameter using adaptive curvature mesh. There are additional advanced options where the user can set the height and base of the tetrahedral. 


\subsection{Boundary conditions}

For bending and impact test simulations, the beam was considered as a simply supported beam as is illustrated in Fig. 7a and b. For bending test, a displacement in the $\mathrm{z}$-axis was applied of $6 \mathrm{~mm}$ according to the failing deflection obtained from the experimental curve in Fig. 8, while displacements and rotations were restricted in other directions. The bending analysis was carried out using roller diameter of $5 \mathrm{~mm}$ that located in the support and loading span and friction factor of 0.4. The total step set to be 100 steps of each interval of $0.02 \mathrm{~s}$. The maximum z-direction stress was obtained from both tension and compression sides. While, the impact analysis was carried out using a $V$-notch specimen and the energy-time-displacement were monitored. The sample has been supported from $A$, $B$ ends of span $60 \mathrm{~mm}$ set as a deformable object, while the hammer set as rigid object that has an impact velocity of $3.8 \mathrm{~m} / \mathrm{s}$ and impact time of $0.001 \mathrm{~ms}$. For the damage criteria and crack initiation in the impact test, the material properties were set for tensile, compression and shear stress of $600,570,90 \mathrm{MPa}$ respectively.

\section{Results and discussion}

The results section divided into three main parts. The first part presents the data of the flexural strength of the specimens, second part presents the impact strength of the specimens and last part presents the outcomes of the FE simulation. In the discussion section, the experimental and simulation values of flexural and impact tests were compared to validate the experimental work.

\subsection{Flexural test}

Force displacement plots in Fig. 8 shows the stiffness of all specimens that fail at $6 \mathrm{~mm}$ deflections. The maximum force is the force at the fracture. The maximum force for each specimen was obtained from averaging 3 specimen tests from same category, it was found that standard deviation was $\pm 5 \mathrm{~N}$ from the fracture force listed in Table 4 . The evolution of phases of deformation in all specimens have three phases as shown in Fig. 8. The three phases deformation are: the linear phase due to elastic modulus, second phase where curve loses its linearity and exhibit non-linear deformation, which considered is the beginning of damage and later phase is the rupture of the specimen.

The experimental results of flexural strength of all specimens were found in the range of $185.78-161.38 \mathrm{MPa}$, which below the specified flexural strength $(300 \mathrm{MPa})$ that provided by Solvay advanced composite. The circular cutout defect shows a significant reduction in its strength. Among the various shaped embedded flaws, circular specimen has minimum fracture strength of $161 \mathrm{MPa}$. This is $13 \%$ reduction in the strength compared with virgin sample. The square hole has the highest incur failing stress of 184.4 MPa.

\subsection{Charpy impact test}

Tthe impact strength on all specimens provide ForceEnergy-Displacement correlations. Figure 9 shows a plot of force-displacement of virgin specimen and cut-out defect specimens and Fig. 10 shows the correlation of energy absorbed with the hammer penetrate and break the sample width.

It is of significant interest to observe from the plot that the circle flaw specimen exhibits minimum force as compared to the rest of the specimens. Similarly, in the Fig. 10 Energy-displacement plot, circular defect specimen absorbs least energy $(0.5 \mathrm{~J})$ compared to $3.53 \mathrm{~J}$ to the virgin sample. According to Solvay advanced composite data sheet, the fracture strength should be with $5.82 \pm 0.1 \mathrm{~J}$ to the virgin sample. However, the measured value was $65 \%$ less than the reported one. In addition, the fracture forces of the flaw samples varied and reduced according to the type of embedded flaws. The maximum impact force of
Fig. 10 Energy-displacement curve recorded of the test specimens
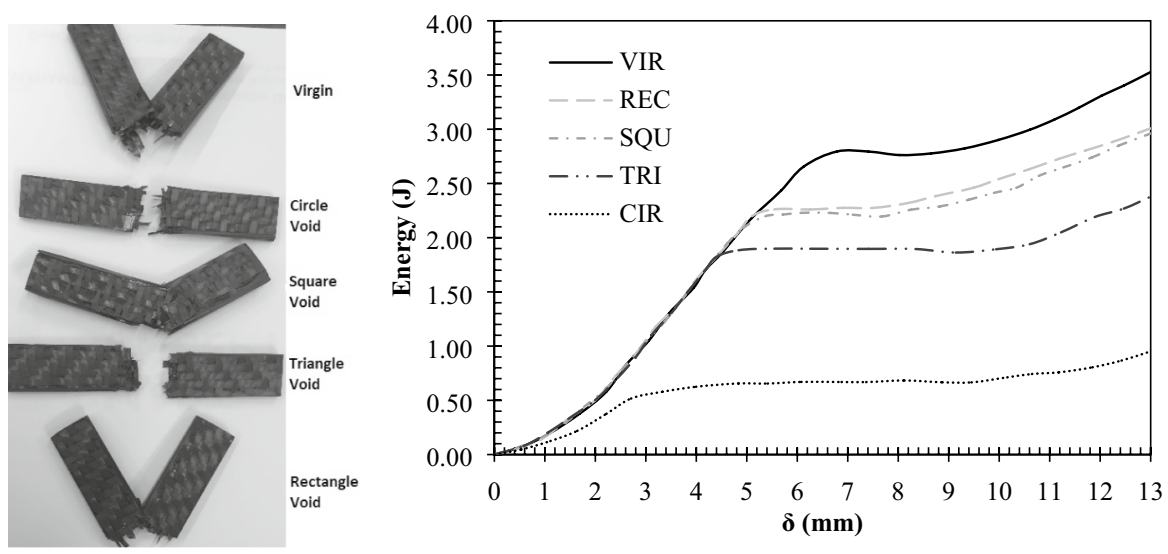

SN Applied Sciences A SPRINGER NATURE journal 
Table 5 Experimental Charpy impact test results

\begin{tabular}{llll}
\hline Specimen & $\mathrm{Fmax}(\mathrm{N})$ & $\begin{array}{l}\text { Impact strength } \\
\mathrm{kJ} / \mathrm{m}^{2}\end{array}$ & $\begin{array}{l}\text { Impact } \\
\text { strength } \\
(\mathrm{J})\end{array}$ \\
\hline Virgin (VIR) & 566.74 & 89.7 & 3.53 \\
Square (SQU) & 565.35 & 78.4 & 2.96 \\
Rectangle (REC) & 566.12 & 73.4 & 3.01 \\
Triangle (TRI) & 567.36 & 53.3 & 2.38 \\
Circle (CIR) & 320.81 & 27.1 & 0.94 \\
\hline
\end{tabular}

circular, rectangular, square and triangular, virgin specimens found to be $320 \mathrm{~N}, 566 \mathrm{~N}, 565 \mathrm{~N}, 567 \mathrm{~N}$ and $566 \mathrm{~N}$ respectively. The effect of circular cut-out defect caused $73 \%$ reduction in absorbed energy due to multiple stress concentration points. The impact strengths are listed in Table 5

\subsection{Fractography}

In the circle shape, the stresses will be experienced in the main (weft yarn) direction and in the bias $\left(45^{\circ}\right)$ direction of the circular specimen. A simple approach to calculate the effective stress concentration factors and axial stress in major axes direction in circular defect in composite laminates called the 'Point Stress Criterion. It is assumed that failure around the circle occurs when the stress at some distance away from the circle is equal to or greater than the virgin laminate strength of the specimen. The other reason for the failure of the circle shape is explained using 'Average Stress Criterion'. It is assumed here that the failure occurs when the average stress over some distance ahead of the circle is equal to the virgin laminate strength of the specimen. However, the third criterion of strain concentration around circle can be explained with the damaged weave, a higher value of strains is found in areas where fibres are oriented perpendicular to the loading direction [14]. A lower value of strain is observed in areas where fibres are oriented parallel to the loading direction. The $2 \times 2$ Twill fibres weaving pattern is oriented so that the weft yarn skip two wrap yarns and go over the third one, hence, the strain concentrations in laminates with circles are influenced by the loose end fibres that will easily break in the direction of load circle, leaving the main stress curried out by the matrix. The angles of the loose fibre will
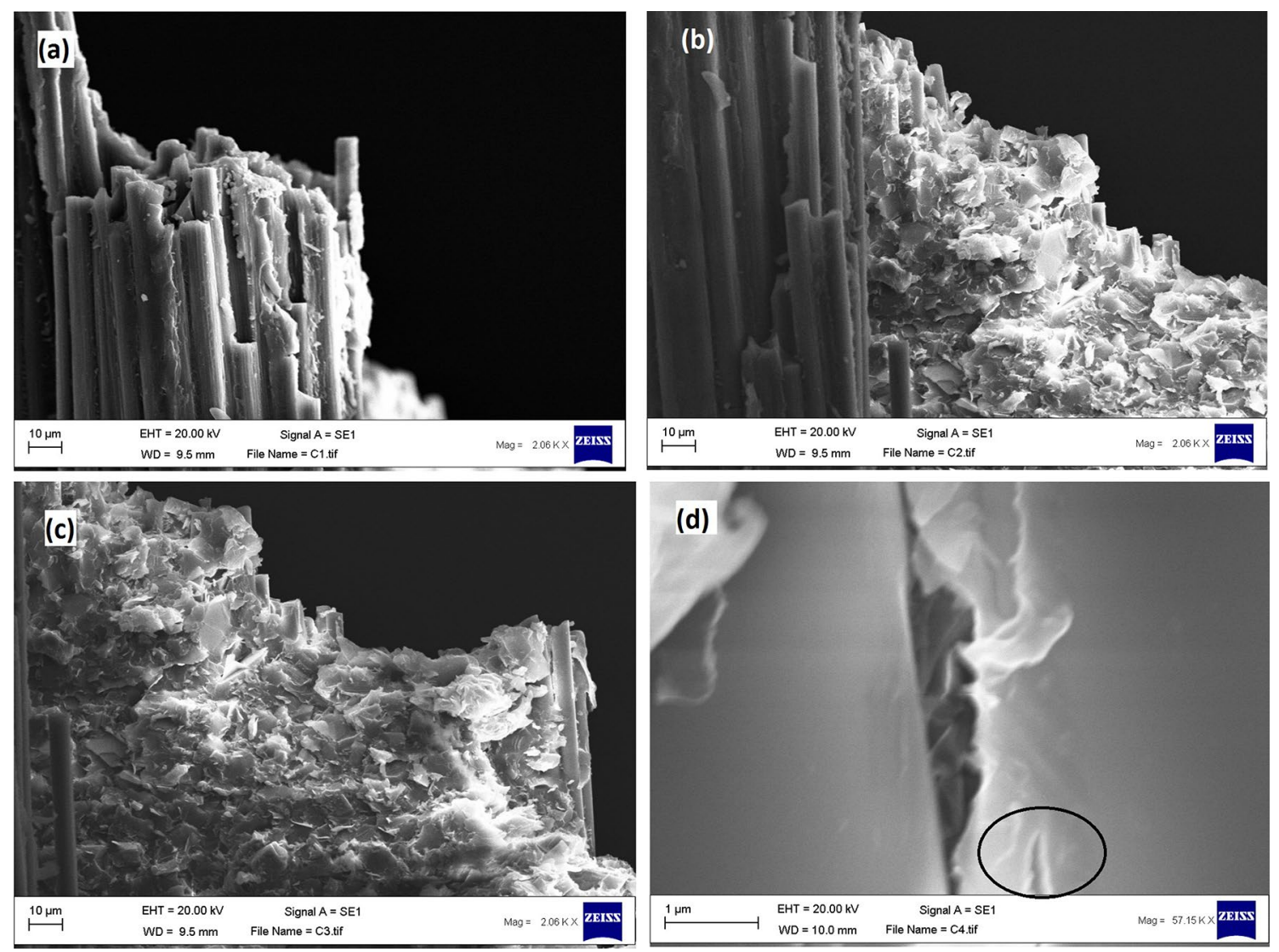

Fig. 11 SEM image of the fracture area in circular void specimen a Bulk virgin specimen fracture area, $\mathbf{b}$ matrix fracture area taken from circumferential area of the defect cut-out, $\mathbf{c}$ matrix and fibre fracture area $\mathbf{d}$ Matrix Nano crack along the direction of the fibre 

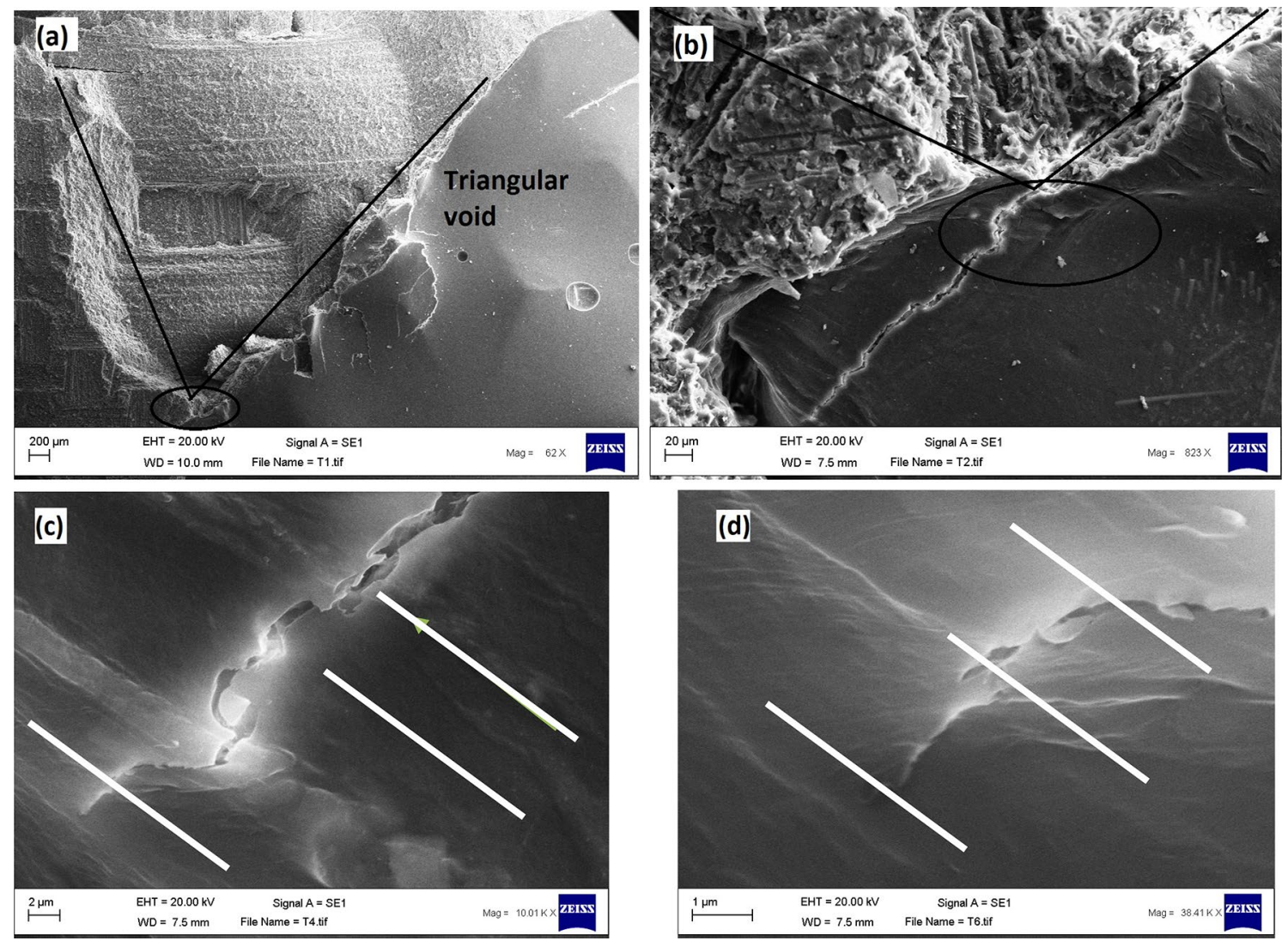

Fig. 12 SEM images of the crack propagation in triangular sample, a bulk stage, $\mathbf{b}$ crack root, $\mathbf{c}$ crack propagation, $\mathbf{d}$ Nano crack path between the fibres

exhibit different mechanical properties at different regions in the circular geometry, hence it will result in matrix crack. The layered composite can be assumed to be orthotropic such that it has three orthogonal planes of material property symmetry.

The scanning electron microscope images shown in Fig. 11 indicates: (a) a fibre pull-out in the virgin sample as bulk visual inspection, while the microstructure failure analysis of defect cut-out area indicate a matrix crack as shown in Fig. 11 b. In the circular sample, all fibres were intact, and no fibre pull-out has been observed at the fracture area as shown in Fig. 12c and a Nano matrix crack has been identified in Fig. 11d.

The fractography examination of the triangular void specimens using scanning electron microscopy shows the cracking area of the specimen in Fig. 12a. In Fig. 12b confirms that a crack exists at tip of the triangular cut-out and progressed across the specimen width in the axial direction with a kink shear band through the ply thickness. A further investigation to the crack growth roots in that fracture area leads to spread smaller longitudinal cracks shown in Fig. 12c. Then, the crack transformation from longitudinal to transverse direction along the fibres were in Fig. 12d. This has been confirmed that matrix crack has been arrested by the fibres that highlighted in white lines in Fig. 12c and d. However, there is no evidence of this crack of being the first crack that material due to fail. A future work should focus on in-depth fractography analysis that use in-situ CT stage mounted in a high-resolution CT X-ray tomography might reveal the root of the first initiated crack.

\subsection{FEA simulation}

The results of the maximum bending stress from all samples were obtained from the simulation were very close from the experimental work. The maximum stress was obtained from virgin, rectangular, triangular and circular samples are shown in Fig. 13. However, no failure has been observed in all samples at $6 \mathrm{~mm}$ deflection.

All tension stresses were higher than the compression stress in all specimens and they were listed in Table 6. No failure mode has been observed, however, a failure in virgin sample has occurred once the deflection increased from 6 to $8 \mathrm{~mm}$ as shown in Fig. 14, a maximum stress of 
Fig. 13 The stress profile of Z-direction Stress of the beam shows the tension $(+)$ and compression (-) for specimens $\mathbf{a}$ virgin, $\mathbf{b}$ rectangular, $\mathbf{c}$ square, d Triangular, e circular cut-out defect
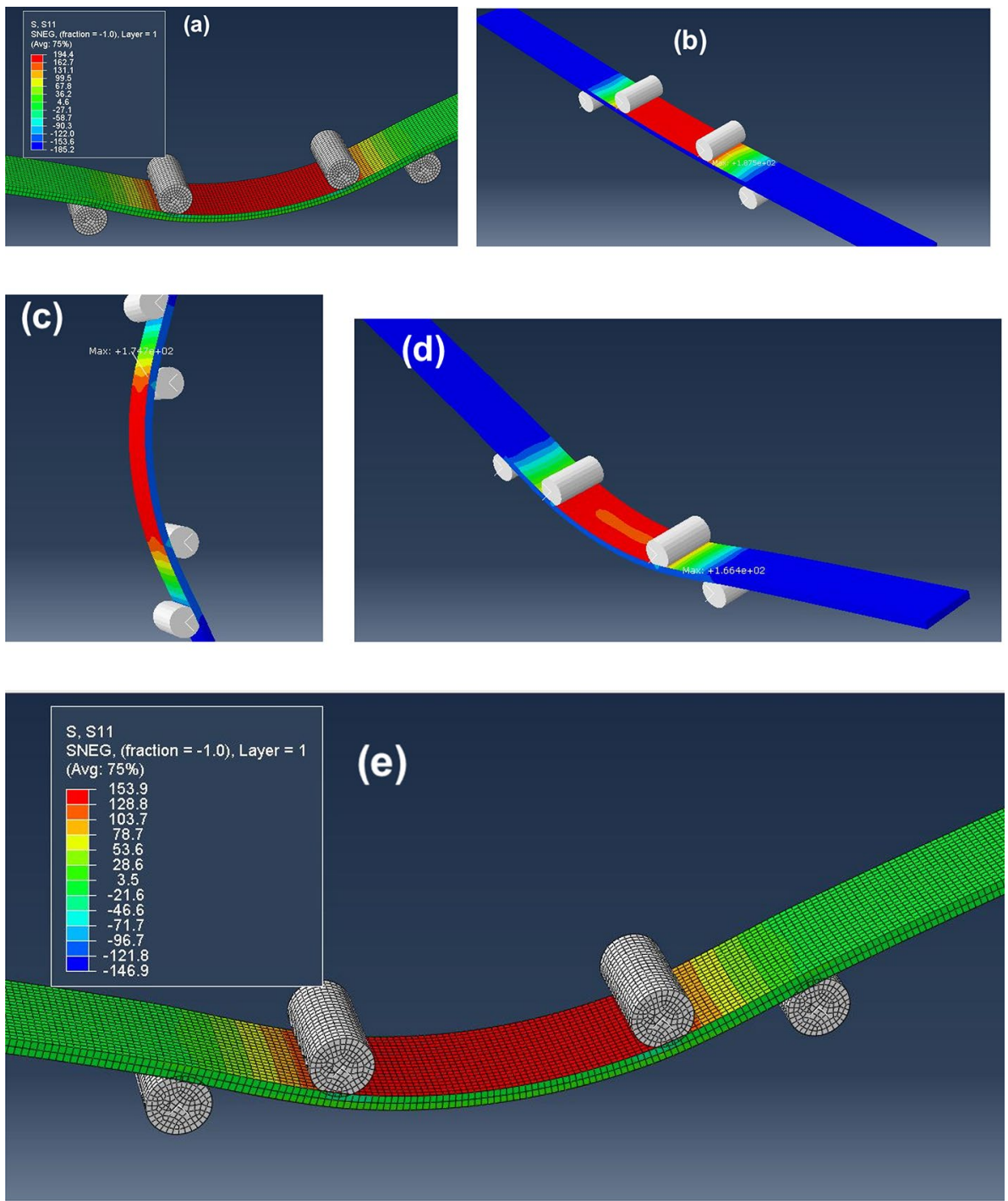

Table 6 List of FEA and EXP Stress values of all samples

\begin{tabular}{lll}
\hline Specimen & EXP $\sigma_{f} \mathrm{MPa}$ & FEA $\sigma_{f} \mathrm{MPa}$ \\
\hline Virgin (VIR) & 185.78 & 194.3 \\
Square (SQU) & 184.4 & 187.3 \\
Rectangle (REC) & 183.5 & 171.5 \\
Triangle (TRI) & 175.87 & 160.9 \\
Circle (CIR) & 161.38 & 153.9 \\
\hline
\end{tabular}

Table 7 Comparison of Energy absorbed in FEA and experimental work (EXP)

\begin{tabular}{lll}
\hline Reference & EXP energy (max) J & FEA energy (max) J \\
\hline Virgin (VIR) & 3.53 & 3.66 \\
Square (SQU) & 2.96 & 2.88 \\
Rectangle (REC) & 3.01 & 3.03 \\
Triangle (TRI) & 2.38 & 2.19 \\
Circle (CIR) & 0.94 & 0.85 \\
\hline
\end{tabular}

Fig. 14 Failure mode of virgin sample at $8 \mathrm{~mm}$ deflection

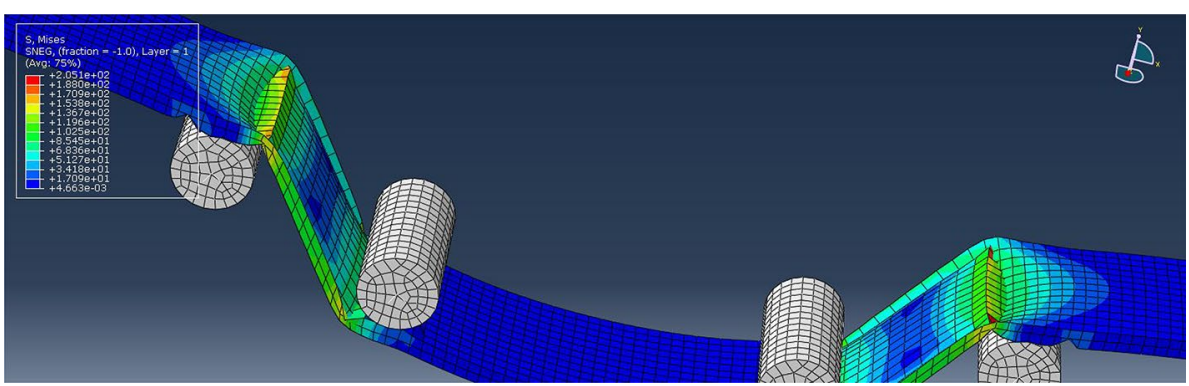




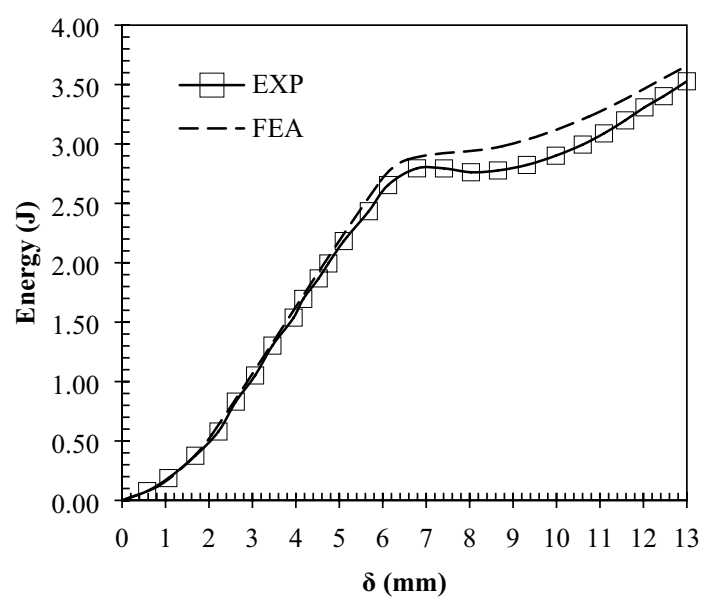

(a) VIR

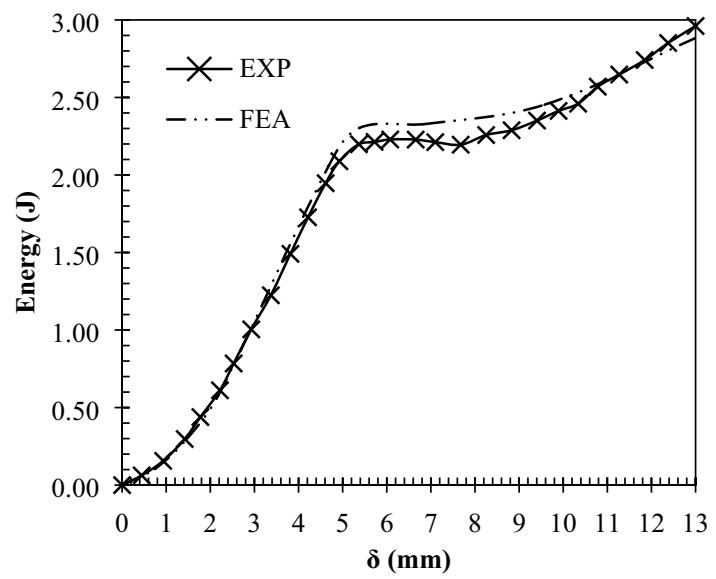

(c) SQU

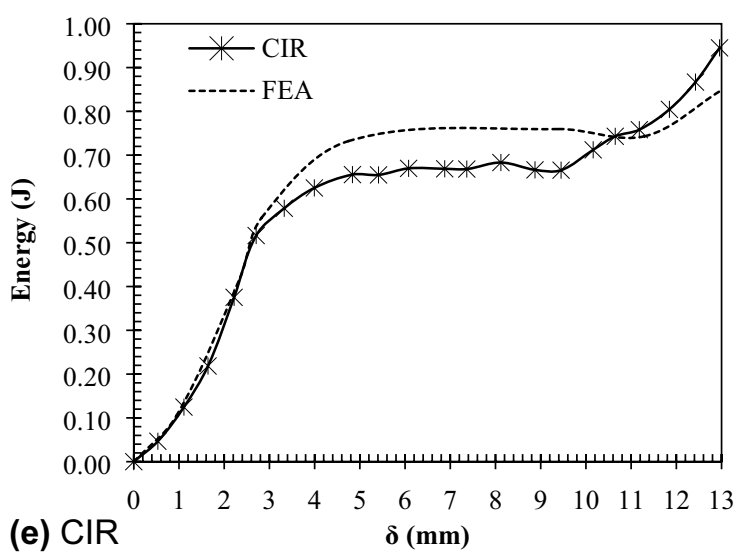

Fig. 15 Comparison of energy-displacement curve between experimental and FEA results, a virgin, $\mathbf{b}$ rectangular, c square, $\mathbf{d}$ Triangular, e circular Though the surface area of the cut-out defect represents $1.8 \%\left(2100 \mathrm{~mm}^{2} / 38.4 \mathrm{~mm}^{2}\right)$ from the entire surface area

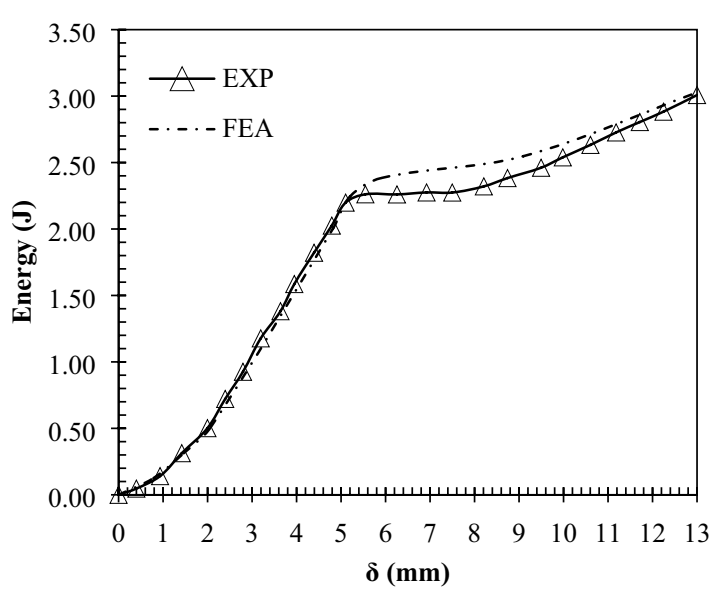

(b) REC

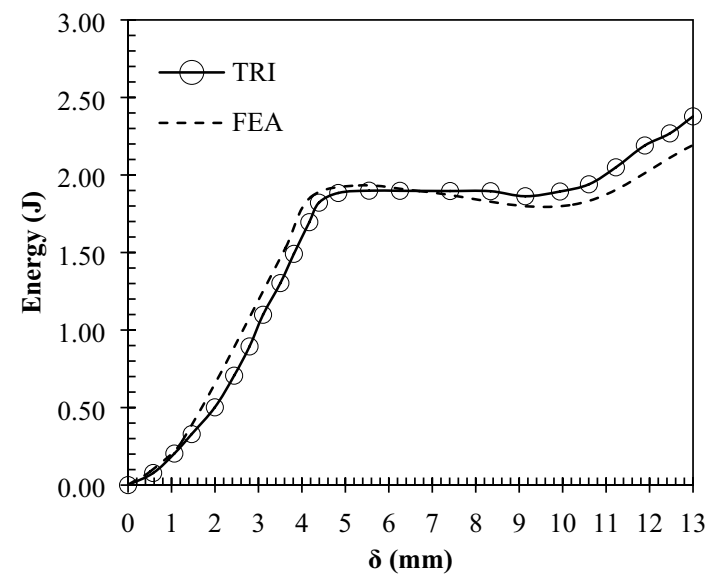

(d) TRI

of specimen, a reduction of $73 \%(3.53-0.94 / 3.53)$ in the impact strength has occurred in case of circle defect specimen. That raises a concern of using ATP as manufacturing process of carbon fibre composite for wing and fuselage aircraft structure 

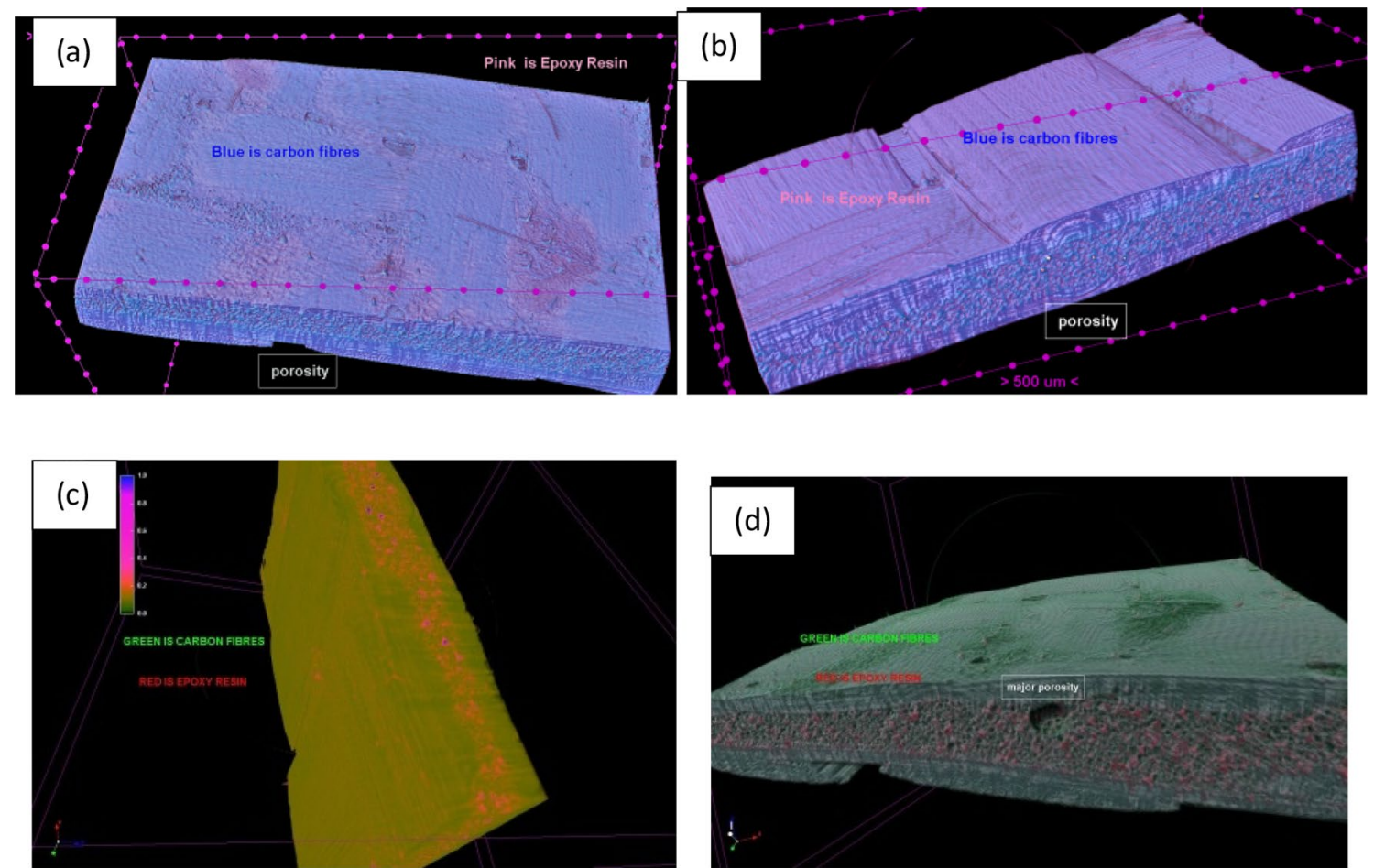

Fig. 16 Images taken from X-ray tomography of specimen size $1 \mathrm{~mm} \times 1 \mathrm{~mm} \times 1 \mathrm{~mm}$ size VRE a virgin sample, $\mathbf{b}$ rectangular sample, $\mathbf{c}$ triangular sample, $\mathbf{d}$ circular sample

$300 \mathrm{MPa}$ has been noted. That value is in agreement with the Solvay material data sheet for flexural strength.

Table 7 presents the obtained maximum tension stresses from both experimental and FE simulation. There is a fair agreement with the experimental work.

\subsection{FEA Charpy impact test result}

Figure 15 shows the FE simulated Energy-displacement plots along with the experimentally acquired results. Plots seem to be in reasonable agreement however as can be seen from Table 7, the specimen with circle embedded flaw is visibly deviated with an error of $10 \%$. This discrepancy between $\mathrm{FE}$ analysis and experimental results could be explained due to the micro buckling that occurred at the notch that is not represented in the FE analysis. The experimental result shows the lower energy absorbed for the damage. FE simulations did not capture the fracture surfaces at the notch and at the cut-out defect hence, precise calculation and interaction between both the cracks could not be accurately captured and analysed.

At the final stage of the analysis, a micro computed X-ray tomography has been deployed using CT scan Bruker Sky scan 2211 to look at 3D imaging of the fibre orientation. This is necessary to ensure that cut-out defect is correctly positioned after curing. A volume representative element (VRE) has been selected from the scan data to achieve high resolution image of 2 microns that shown in Fig. 16. The x-ray source voltage was set $30 \mathrm{kV}$, no filter was used, and sample was mounted on a precision air bearing rotation stage with less than $50 \mathrm{~nm}$ accuracy to achieve the high-resolution images that shown in Fig. 16. Figure 16a shows VRE of the virgin sample cross section, no twist, Knick in the fibre have been observed. While, a circular defect specimen is shown in Fig. 16d at the 3rd ply using sectional clip in CT Analyser software. A considerable porosity has been detected and highlight in red colour in Fig. 16c and d. Other defect samples were CT scanned, and the cut-out defects were not identified. We suggest that the epoxy resin might flow into the defect during curing and fill completely that make it a difficult to detect in this test.

\section{Conclusion}

In this study, the bending and impact strength of laminated composite with and without cut-out defect have been investigated. FE simulation was performed for each specimen to validate the bending and impact test results. Based on the result of the present investigation, following findings can be summarised:

1. Virgin laminate specimen was able to carry the maximum flexural strength to break, while circle cut-out

\section{SN Applied Sciences}


specimen showed a reduction of $13 \%$ in its flexural strength. However, the experimental fracture stress of the virgin beam (194 MPa) was less that simulation and manufacture data sheet value of $300 \mathrm{MPa}$.

2. Virgin laminate specimen has absorbed the maximum impact energy to break, while circle specimen shows a reduction of $73 \%$ in absorbed energy to break. However, impact strength of the virgin sample was far less that the manufacture data sheet due to porosity trap between plies shown in Fig. 16.

3. Fibre pull-out failure mode has been observed in the virgin specimen, while matrix crack was the dominant failure mode in other specimens. It was demonstrated that Nano cracks can been arrested by the longitudinal fibers weaving pattern.

4. The strain concentrations in twill weaved laminates have circular cut-out fibers are influenced by the loose end fibres that will easily break in the direction of load in the circle, leaving the main stress curried out by the matrix. The angles of the loose Fibre will exhibit stress miscarriage at different regions in the circular geometry, hence it will result in a matrix crack.

5. Though the surface area of the cut-out in the laminate sample represents $1.8 \%\left(2100 \mathrm{~mm}^{2} / 38.4 \mathrm{~mm}^{2}\right)$ of the entire Fibre surface area, a reduction of $73 \%$ in the impact strength has occurred in case of circle cut out. This reduction raises a concern of using ATP process for manufacturing aircraft wing where cut-out defect could compromise its structure integrity.

6. A future work should focus on in-depth fractography analysis that use in-situ CT stage mounted in a highresolution CT X-ray tomography might reveal the root of the first initiated crack that cause failure. This will reinforced the idea of using ATP for manufacturing wing structure could compromise passenger safety.

Acknowledgements This study was partially supported by the School of Engineering at University of Wolverhampton.

\section{Compliance with ethical standards}

Conflict of interest The authors declare that they have no competing interests.

\section{References}

1. Caminero MA, Rodríguez GP, Muñoz V (2016) Effect of stacking sequence on Charpy impact and flexural damage behavior of composite laminates. Compos Struct. https://doi.org/10.1016/j. compstruct.2015.10.019

2. Caminero MA, Rodríguez GP, Chacón JM, García-Moreno I (2019) Tensile and flexural damage response of symmetric angle-ply carbon fiber-reinforced epoxy laminates: non-linear response and effects of thickness and ply-stacking sequence. Polym Compos. https://doi.org/10.1002/pc.25230

3. Caminero MA, García-Moreno I, Rodríguez GP (2018) Experimental study of the influence of thickness and ply-stacking sequence on the compression after impact strength of carbon fibre reinforced epoxy laminates. Polym Test. https://doi. org/10.1016/j.polymertesting.2018.02.009

4. Bari K, Arjunan A (2019) Extra low interstitial titanium based fully porous morphological bone scaffolds manufactured using selective laser melting. J Mech Behav Biomed Mater. https://doi. org/10.1016/j.jmbbm.2019.03.025

5. Caminero MA, Lopez-Pedrosa M, Pinna C, Soutis C (2013) Damage monitoring and analysis of composite laminates with an open hole and adhesively bonded repairs using digital image correlation. Compos Part B Eng. https://doi.org/10.1016/j. compositesb.2013.04.050

6. Lyssakow P, Friedrich L, Krause $\mathrm{M}$ et al (2020) Contactless geometric and thickness imperfection measurement system for thin-walled structures. Measurement. https://doi.org/10.1016/j. measurement.2019.107038

7. Luca Francesco AD (2017) A review on analytical failure criteria for composite materials. AIMS Mater Sci 4:1165-1185. https:// doi.org/10.3934/matersci.2017.5.1165

8. Naik NK, Ramasimha R (2001) Estimation of compressive strength of delaminated composites. Compos Struct. https:// doi.org/10.1016/S0263-8223(00)00168-9

9. Short GJ, Guild FJ, Pavier MJ (2001) The effect of delamination geometry on the compressive failure of composite laminates. Compos Sci Technol. https://doi.org/10.1016/S0266 -3538(01)00134-8

10. Wang B, Ma X, Hao P et al (2019) Improved knockdown factors for composite cylindrical shells with delamination and geometric imperfections. Compos Part B Eng 163:314-323. https://doi. org/10.1016/j.compositesb.2018.11.049

11. Park DY, Lee SY (2012) Parametric effects on embedded delamination buckling in composite structures using the EAS threedimensional element. Compos Part B Eng 43:1800-1812. https ://doi.org/10.1016/j.compositesb.2012.02.033

12. Riccio A, Scaramuzzino F, Perugini P (2001) Embedded delamination growth in composite panels under compressive load. Compos Part B Eng 32:209-218. https://doi.org/10.1016/S1359 -8368(00)00057-3

13. Kharghani N, Guedes Soares C (2016) Behavior of composite laminates with embedded delaminations. Compos Struct 150:226-239. https://doi.org/10.1016/j.compstruct.2016.04.042

14. Toubal L, Karama M, Lorrain B (2005) Stress concentration in a circular hole in composite plate. Compos Struct 68:31-36. https ://doi.org/10.1016/j.compstruct.2004.02.016

Publisher's Note Springer Nature remains neutral with regard to jurisdictional claims in published maps and institutional affiliations. 